\title{
0 Direito de Consulta aos Povos Indígenas à Luz da Teoria Geral dos Direitos Fundamentais
}

\author{
The Consultation Right to Indigenous Peoples in the Light of the General \\ Theory of Fundamental Rights
}

\author{
JULIANNE HOLDER DA CÂMARA SILVA FEIJÓ \\ Professora da Universidade Federal Rural do Semi-Árido (Ufersa), Vice-Coordenadora do Curso \\ de Direito da Ufersa, Mestre em Direito Constitucional pela Universidade Federal do Rio Gran- \\ de do Norte (UFRN), Ex-Bolsista do Programa de Formação de Recursos Humanos em Direito \\ do Petróleo e Gás Natural (PRH - 36 ANP), Graduada pela UFRN.
}

Submissão: 20.07.2015

Decisão Editorial: 27.08.2015

Comunicação ao Autor: 27.08.2015

RESUMO: A Constituição brasileira de 1988, estendendo o seu manto protetor sobre as minorias étnicas nacionais, reconheceu a sua importância para a formação da identidade do povo brasileiro, dedicando capítulo exclusivo à proteção dos indígenas, revelando a intenção do constituinte de garantir a sua reprodução física e cultural, abandonando o fantasma da integração. Para tanto, a Constituição previu alguns direitos instrumentais, tais como direitos territoriais, usufruto exclusivo dos recursos naturais e o direito de consulta quando determinados empreendimentos econômicos pretendam se instalar em terras indígenas. 0 direito de consulta surge, assim, como um direito fundamental das comunidades índias por atrelar-se a sua reprodução física e cultural, inarredável da materialização da dignidade indígena. Nesse contexto, o presente ensaio se debruçará sobre o direito de consulta aos povos indígenas, analisando-o à luz da teoria geral dos direitos fundamentais, que revela um direito misto, encerrando características de verdadeiro direito de participação, ao mesmo tempo em que exige uma prestação por parte do Estado brasileiro, que, apesar de se manter inconstitucionalmente inerte nesses quase trinta anos de Constituição, apresenta regulação específica a partir do momento em que incorporou ao ordenamento jurídico nacional, com status de lei ordinária, documentos internacionais dedicados à regulação do processo consultivo. 0 descumprimento sistemático dessas normas, além de ferir o direito subjetivo das populações indígenas, ainda desprestigia e desacredita o País em suas relações internacionais, em uma verdadeira vergonha nacional.

PALAVRAS-CHAVE: Povos indígenas; direito de consulta; teoria geral dos direitos fundamentais. 
ABSTRACT: The Brazilian Constitution of 1988, extending its protective mantle on national ethnic minorities, recognized its importance for the formation of the identity of the Brazilian people, dedicating entire chapter to the protection of indigenous, revealing the intention of the constituent to ensure their physical and cultural reproduction, abandoning the integration of the ghost. Therefore the Constitution foresaw some instrumental rights, such as land rights, exclusive use of natural resources and the right to consultation when certain economic enterprises wishing to settle on Indian lands. The consultation of law arises, as well as a fundamental right of Indian communities by tying up their physical and cultural reproduction, unwavering materialization of indigenous dignity. In this context, this paper will look at the right of consultation of indigenous peoples, analyzing it in the light of the general theory of fundamental rights, which reveals a mixed right, ending features of genuine right of participation, while requiring a provision by the Brazilian State, although remaining inert unconstitutionally these nearly thirty years of Constitution has specific regulation from the moment he entered the national legal system, with status of ordinary law, international documents devoted to regulation of the consultative process. The systematic breach of these standards and injured subjective right of indigenous peoples also discredits and discredits the country in its international relations, in a real national disgrace.

KEYWORDS: Indigenous peoples; right of consultation; general theory of fundamental rights.

SUMÁRIO: Introdução; 1 Os direitos culturais na perspectiva da teoria geral dos direitos fundamentais; 20 direito de consulta aos povos indígenas; $2.1 \mathrm{~A}$ consulta como um direito fundamental à prestação; 2.2 A consulta como um direito fundamental de participação; 2.30 direito de consulta na Convenção no 169 da OIT; Conclusões; Referências.

\section{INTRODUÇÃO}

Desde a década de 70 debate-se a viabilidade da construção do complexo hidrelétrico de Belo Monte, no Rio Xingu, Estado do Pará, e a causa ganhou notoriedade internacional em 1989, quando lideranças indígenas se reuniram no I Encontro dos Povos Indígenas do Xingu, em Altamira, no Pará, para protestar contra o empreendimento. Os indígenas temiam que se repetisse em Belo Monte o mesmo quadro social e ambiental desastroso evidenciado na construção das hidrelétricas de Tapajós, Tucuruí e Balbina, empreendimentos realizados à total revelia das comunidades índias afetadas.

Em 2008, no mesmo local, fora realizado o II Encontro dos Povos Indígenas do Xingu, com os mesmos propósitos. Nesse meio tempo, lideranças indígenas denunciaram no cenário internacional o descaso com que o Estado brasileiro vem tratando a questão indígena no País, fazendo letra morta dos dispositivos constitucionais destinados à proteção da reprodução física e cultural das minorias nacionais.

A mídia alardeia diuturnamente noticias quanto à problemática de Belo Monte, revelando que copiosamente os interesses sociais e ambientais de minorias nacionais, teoricamente protegidas, em um Estado teoricamente democrá- 
tico, sucumbem à força esmagadora dos interesses econômicos, tudo avalizado pelo Estado brasileiro, pela Suprema Corte do País e pelo órgão indigenista, que, oficialmente, deveria zelar pelos interesses dos índios, mas age de encontro às suas reivindicações e aos seus clamores.

Todos os conflitos em torno da hidrelétrica de Belo Monte gravitam em torno da não observância de direitos constitucionalmente assegurados aos indígenas, principalmente quanto ao direito de consulta às comunidades impactadas, um direito que visa a promover a dignidade dos povos indígenas e a concretização do princípio democrático.

Nesse contexto, o presente ensaio visa a demonstrar, à luz da teoria geral dos direitos fundamentais, a relevância do direito de consulta para as comunidades indígenas, revelando a sua aptidão para materializar a dignidade humana em seu favor, possibilitando a participação dos mesmos nos processos decisórios que possam Ihes afetar, consubstanciando verdadeiro direito fundamental dos índios, ainda que não inscrito no art. 5ํㅜ da Constituição.

Demonstraremos o caráter misto do direito de consulta, que, além de consubstanciar verdadeiro direito fundamental à participação, realizador do princípio democrático e da cidadania indígena, representa, ainda, um direito fundamental à prestação, tanto jurídica quanto material, exigível do Estado brasileiro como um direito subjetivo das comunidades indígenas que devem ver o seu direito satisfeito, nem que seja pela via judicial.

Por fim, encerraremos com uma análise detalhada do procedimento consultivo regulado pela Convenção no 169 da Organização Internacional do Trabalho, incorporada ao nosso ordenamento jurídico com o status de lei ordinária, devendo ser observado pelo Estado brasileiro a fim de que se mantenha dentro da constitucionalidade e em cumprimento de suas obrigações assumidas na ordem internacional perante as demais Nações soberanas.

\section{OS DIREITOS CULTURAIS NA PERSPECTIVA DA TEORIA GERAL DOS DIREITOS FUNDAMENTAIS}

Na evolução histórica do constitucionalismo, a cultura passou a integrar documentos constitucionais a partir da Constituição mexicana de 1917, seguida da Constituição de Weimar, Alemanha, em 1919. No Brasil, foi por meio da Constituição de 1934. Entretanto elas abordavam apenas aspectos de liberdades individuais, como direitos autorais e liberdade de manifestação do pensamento ${ }^{1}$. Foi somente por volta da década de 70, após a derrocada de regimes ditatoriais, fascistas e militares, que surgiu a noção de direitos culturais

1 SILVA, José Afonso da. Ordenação constitucional da cultura. São Paulo: Malheiros, 2001. p. 39. 
como um direito fundamental, indispensável à realização da personalidade do ser humano em um contexto de pluralidade social.

No segundo pós-guerra, de maneira incipiente, mas já com a característica da universalidade, os direitos culturais ganham espaço na Declaração Universal dos Direitos Humanos, de 10 de dezembro de 1948², como direitos necessários à realização do bem-estar do ser humano. Posteriormente, em 19 de dezembro de 1966, ampliando o elenco de proteção aos direitos culturais previstos na Declaração Universal fora firmado o Pacto Internacional de Direitos Econômicos, Sociais e Culturais ${ }^{3}$, revestido da roupagem de tratado internacional, contendo preceitos jurídicos vinculantes para os seus signatários ${ }^{4}$.

Em 10 de dezembro de 2008, fora aprovado um importante instrumento de fiscalização e controle do cumprimento dos preceitos constantes no referido pacto: O Protocolo facultativo ao Pacto Internacional de Direitos Econômicos, Sociais e Culturais, consolidando a capacidade processual dos indivíduos na esfera internacional, que poderão peticionar junto ao Comitê de Direitos Econômicos, Sociais e Culturais da Organização das Nações Unidas (ONU) quando violados os seus direitos constantes no Pacto Internacional de Direitos Econômicos, Sociais e Culturais. Podendo, inclusive, o Comitê requisitar ${ }^{5}$ ao Estado-parte a adoção de medidas urgentes, a fim de evitar violações irreparáveis desses direitos ${ }^{6}$.

No Brasil, o momento histórico de fundamentalização dos direitos culturais remonta à redemocratização do País, no final da década de 80 , quando as minorias ganharam visibilidade política e social, revelando a diversidade cultural formadora da identidade do povo brasileiro, uma diversidade duplamente merecedora de proteção, tanto por corresponder às origens da formação cultural do País como por representar o direito de diversas minorias nacionais em se reproduzir culturalmente, mantendo as suas origens e tradições, livre de qualquer imposição forçada de um paradigma cultural monista.

2 A Declaração Universal dos Direitos Humanos fora provada a unanimidade por 48 Nações, sem ressalvas, e oito abstenções (Bielo-Rússia, a então Checoslováquia, Polônia, Arábia Saudita, Ucrânia, a então URSS, África do Sul e luguslávia).

3 Aprovado pelo Decreto Legislativo $\mathrm{n}^{\circ}$ 226, de 12 de dezembro de 1991, e definitivamente incorporado ao nosso ordenamento jurídico por meio do Decreto n 591, de 6 de julho de 1992.

4 PIOVERSAN, Flávia. Direitos humanos e o direito constitucional internacional. 11. ed. São Paulo: Saraiva, 2010. p. 178.

5 Idem, p. 189

6 Outro instrumento internacional apto a ser manejado pelas populações indígenas em face da inobservância de seus direitos culturais por parte do Estado brasileiro seria demandar junto à Comissão Interamericana de Direitos Humanos, com competência, inclusive, para levar a causa ao julgamento perante à Corte Interamericana de Direitos Humanos, conforme a Convenção Americana de Direitos Humanos (Pacto de São José da Costa Rica), de 22 de novembro de 1969, ratificada pelo Brasil em 25 de setembro de 1992, definitivamente incorporado ao nosso ordenamento jurídico por meio do Decreto $n^{\circ} 678$, de 6 de novembro de 1992. 
Ampliando os horizontes de proteção à cultura, a Constituição Federal (CF) de 1988 optou por conferir especial tratamento a grupos culturais específicos, especiais, que historicamente contribuíram, e ainda contribuem, com a sua riqueza cultural para a formação da identidade do povo brasileiro, tais como indígenas e quilombolas ${ }^{7}$. Ainda concedeu reconhecimento e proteção as manifestações dos diversos grupos participantes do processo civilizatório nacional, o que incluiria a cultura erudita e imigrante (italiana, japonesa, alemã, entre outras) ${ }^{8}$.

Saliente-se que a cultura consiste em uma atitude humana que impregna de valores um objeto natural (bens da natureza, que existem por si só) ou social (comportamentos, atividades, produtos e interesses característicos de um povo), em uma verdadeira transformação da realidade ${ }^{9}$. Só o homem cria cultura, que é algo construído (atribuição de valores a objetos naturais e sociais). Antropologicamente, todos os artefatos e criações da obra humana são cultura, mas nem toda essa expressão cultural está abarcada pela proteção constitucional ${ }^{10}$.

A Constituição ampara a cultura no sentido de referência à identidade, à ação e à memória dos diferentes grupos formadores da sociedade brasileira ${ }^{11}$. De fato, afora o capítulo reservado à cultura, a Constituição Federal de 1988 ainda dedicou um capítulo exclusivo para tratar da questão indígena ${ }^{12}$, bem como assegurou direitos territoriais às comunidades quilombolas ${ }^{13}$, tombando todos os seus sítios e documentos históricos (art. 216, § 5º), revelando a importância que o constituinte atribuiu à participação desses grupos na formação da matriz cultural brasileira.

Ao reservar um capítulo dedicado aos povos indígenas, a Constituição Federal de 1988 pretendia mais do que regular a situação dos índios no Brasil, objetivava dar proteção aos seus interesses e assegurar direitos essenciais à reprodução física e cultural dessas comunidades, reconhecendo que vivem um estilo de vida tradicional, com cultura, línguas, tradições e religiosidade que Ihes são peculiares, diversos da sociedade envolvente e que por ela deveriam ser respeitados e protegidos contra qualquer forma de dominação ou imposição.

A Constituição brasileira rompe com a tradição histórica de compreender o ser indígena como uma situação transitória, fadada à incorporação ao estilo

7 Ainda reconheceu a importância de proteger a cultura popular brasileira, que, no dizer de José Afonso, trata-se das manifestações culturais das diversas camadas do povo, não apresentando, pois, uniformidade (Op. cit., p. 76).

8 SILVA, José Afonso da. Op. cit., 2001, p. 85.

9 Idem, p. 32.

10 Idem, p. 34-35.

11 Idem, p. 114.

12 Capítulo VIII, inserido no Título VIII - "Da Ordem Social”, arts. 231 e 232.

13 Art. 68 do Ato das Disposições Constitucionais Transitórias (ADCT). 
de vida "dominante", transformando-o em autêntico cidadão brasileiro, perdendo, com isso, o seu status de indígena e todos os direitos correlatos. Abandonando o paradigma de assimilação, ao reconhecer as tradições culturais indígenas como um direito e um dever de proteção do Estado, a Constituição Federal assegurou ao índio o direito a continuar sendo índio, sem o fantasma da aculturação forçada que pairou no ordenamento jurídico pátrio desde a época colonial ${ }^{14}$.

O Brasil é uma nação por demais cosmopolita, formada, ao longo de sua evolução histórica, por uma diversidade cultural imensurável. Diversos foram os povos indígenas, africanos e europeus que aqui conviveram e se misturaram, deixando a sua marca indelével na formação da identidade brasileira. Se fosse possível resumir o povo brasileiro em uma única palavra, certamente seria diversidade a palavra mais apropriada.

Ensina José Afonso da Silva ${ }^{15}$ que, para entendermos a preocupação da Constituição em proteger as referências culturais dos diversos grupos formadores do povo brasileiro, seria necessário um enquadramento da Constituição no contexto histórico do processo civilizatório nacional, voltando-se para os três principais grupos étnicos responsáveis pela nossa miscigenação: índios, negros e portugueses. Lembra, ainda, o autor que esses grupos, por si só, já apresentavam variações étnicas internas ${ }^{16}$, somados, ainda, aos imigrantes alemães, italianos e japoneses responsáveis por introduzir novas matizes culturais a partir da segunda metade do século XIX, o que nos leva a concluir, por tanto, que a miscigenação brasileira se deu entre grupos deveras diversificados, resultando em uma mistura genética e cultural única, formadora da identidade brasileira.

Reconhecendo essa nossa característica, e almejando conceder proteção jurídica a essa riqueza cultural, a CF, em seu art. 215, § 1ํㅡㄹ determinou que "o Estado protegerá as manifestações das culturas populares, indígenas e afro-brasileiras, e das de outros grupos participantes do processo civilizatório nacional", além de promover "defesa e valorização do patrimônio cultural brasileiro" e "valorização da diversidade étnica e regional" (art. 215, § 3으, I e V). Em sequência, em seu art. 216, a Carta afirma que "constituem patrimônio cultural brasileiro os bens de natureza material e imaterial, tomados individualmente ou em conjunto, portadores de referência à identidade, à ação, à memória dos diferentes grupos formadores da sociedade brasileira".

14 Maiores informações quanto ao paradigma da assimilação ou integração, vide: FEIJÓ, Julianne Holder da C. S. A capacidade civil indígena. Revista Direitos Fundamentais e Justiça, v. 8, n. 28, p. 223 (A 2), jul./set. 2014.

15 SILVA, José Afonso da. Op. cit., 2001, p. 75.

16 Os diversos povos indígenas que se espalhavam pelo Brasil quando de sua colonização se originavam de quatro grandes grupos étnicos: Os Caraíbas, os Jês, os Tupis e os Maruaques; por sua vez, os negros africanos escravizados trazidos para o Brasil se originavam de dois grupos étnicos: Os Bantos e os Sudaneses. 
Dessa novidade constitucional algumas consequências relevantes se fazem notar. De início - relembrando que a Constituição não se trata de um documento neutro ${ }^{17}$, mas constituído à luz de valores relevantes para a sociedade brasileira $^{18}$-, temos que a proteção à reprodução física e cultural dos povos indígenas foi uma opção clara e cristalina do legislador constituinte, isso porque proporcionar meios e condições jurídicas e materiais para a manutenção e o respeito à diversidade étnica e cultural representa uma forma de efetivar a igualdade entre os diversos componentes do povo brasileiro, concretizando a dignidade em seu favor.

O pluralismo é uma realidade brasileira, e a diversidade de grupos sociais, econômicos, étnicos e ideológicos que aqui convivem conduziu o legislador constituinte à opção por uma democracia pluralista (opção clara desde o seu preâmbulo), o que significa acolher uma sociedade conflituosa, concedendo-lhe a satisfação das múltiplas necessidades e antagonismos que encerra, dedicando-se, a ordem constitucional, à construção do equilíbrio entre esses interesses diversos. Cada demanda, oriunda dos variados grupos integrantes da sociedade brasileira, deverá ser atendida, dentro de suas especificidades e no interior do sistema de valores constitucionais, a fim de que a Constituição logre obter legitimidade, concretizando o princípio democrático, materializando a dignidade humana para todos.

No capítulo dedicado aos indígenas, art. 231, caput, a Carta inicia reconhecendo aos "índios sua organização social, costumes, línguas, crenças e tradições, e os direitos originários sobre as terras que tradicionalmente ocupam", revelando a intenção de garantir a reprodução cultural dos povos indígenas, inarredável de sua reprodução física. Em seu art. 210, § 1ํㅡ, a Constituição assegura que o "ensino fundamental regular será ministrado em língua portuguesa, assegurada às comunidades indígenas também a utilização de suas línguas maternas e processos próprios de aprendizagem", deixado claro a intenção de manter e reproduzir os hábitos culturais dos gentios, inclusive por meio do direito básico à educação.

A Carta vai mais além e garante meios que viabilizem essa reprodução física e cultural dos índios: assegura os seus direitos originários sobre as terras que tradicionalmente habitam, bem como as necessárias ao seu bem-estar e às suas atividades produtivas, além de garantir o usufruto exclusivo dos recursos naturais presentes em suas terras (art. 231, $\S \S 1^{\circ}$ e $2^{\circ}$ ).

17 Citando decisão histórica do Tribunal Constitucional alemão, no caso Lüth, em 1958, Vide: BRANCO, Paulo Gustavo Gonet. Aspectos de teoria geral dos direitos fundamentais. In: MENDES, Gilmar Ferreira; COELHO, Inocêncio Mártires; BRANCO, Paulo Gustavo Gonet. Hermenêutica constitucional e direitos fundamentais. Brasília: Brasília Jurídica, 2000. p. 177. 
Tais direitos são instrumentais, visam a alcançar o objetivo maior de garantir a reprodução física e cultural dos indígenas, propiciando as condições materiais que satisfaçam o seu bem-estar e a sua dignidade. Somente assegurando a possibilidade de o indígena praticar as suas tradições, a sua cultura e a sua religiosidade (sem que isso acarrete qualquer perda de direitos) é que se concretiza o valor dignidade humana, basilar em nossa ordem constitucional, para as diversas comunidades indígenas que convivem no território brasileiro. Assegurar a igualdade entre os integrantes do povo brasileiro significa, antes de tudo, reconhecer a diversidade (o pluralismo social), concedendo-lhe meios de se reproduzir sem qualquer imposição de homogeneização.

Do exposto, nos deparamos com alguns valores fundamentais para um Estado Democrático de Direito: dignidade humana, igualdade e pluralismo. Opções políticas feitas pelo legislador constituinte que se traduzem em princípios constitucionais que passam a influenciar toda a ordem jurídica e a limitar e direcionar a atividade dos Poderes Públicos, de modo que não só existe um direito subjetivo de cada índio e de cada comunidade indígena ${ }^{19}$, à reprodução cultural e à identidade étnica (acepção subjetiva dos direitos fundamentais) oponível ao Estado e à sociedade, como passa a existir um dever do Estado de tomar medidas tendentes a proteger e concretizar tais direitos (acepção objetiva dos direitos fundamentais) que se convertem em verdadeiros princípios direcionadores da atividade estatal.

Por oportuno, saliente-se que, apesar de não inscrito no art. $5^{\circ}$ da Constituição, o direito à reprodução cultural não perde o seu status de fundamentalidade, correspondendo a um verdadeiro direito materialmente fundamental, posto que indispensável a realização da dignidade humana para relevantes segmentos sociais. Não seria a inscrição no rol de direitos constante no art. $5^{\circ}$ da Constituição que identificaria um direito como fundamental, mas a sua aptidão para promover a dignidade humana, não sendo, pois, aquele rol taxativo ${ }^{20}$. Seriam fundamentais aqueles direitos que, caso negados aos indivíduos, se estaria retirando a sua dignidade enquanto ser humano.

De fato, a nossa Suprema Corte ${ }^{21}$ já se posicionou pela não taxatividade dos direitos fundamentais elencados no art. 5ํㅜ da Carta Magna, reconhecendo como materialmente fundamental o direito não inscrito em seu rol. Com efeito,

19 Os direitos indígenas possuem uma expressão coletiva, dado que são titularizados por cada comunidade enquanto grupo, haja vista a forte noção do coletivo presente nas diversas culturas indígenas espalhas pela América. Dessa forma, o direito à reprodução cultural afeta não só o índio isoladamente considerado, como toda a comunidade ao qual ele pertence, enquanto ser coletivo, bem como a todos os povos indígenas em geral.

20 BRANCO, Paulo Gustavo Gonet. Op. cit., 2000, p. 160.

21 Julgamento da ADIn 939, DJ 18.03.1994, quando o Supremo Tribunal Federal (STF) declarou que o princípio da anterioridade tributária, previsto no art. 150, III, $b$, da CF, constituía um direito ou uma garantia individual fundamental, ainda que não inscrito no art. $5^{\circ}$ da Constituição. 
o próprio art. $5^{\circ}$, em seu $\S 2^{\circ}$, aduz que "os direitos e garantias expressos nesta Constituição não excluem outros decorrentes do regime e dos princípios por ela adotados, ou dos tratados internacionais em que a República Federativa do Brasil seja parte", deixando bem claro o caráter aberto daquele rol de direitos.

Ainda à luz da teoria geral dos direitos fundamentais, observamos que os direitos culturais reunidos na Constituição Federal de 1988 se apresentam em duas facetas, uma individual, titularizada por cada indivíduo alvo dessa proteção, como cada índio ou outro integrante de um grupo étnico específico, que possui o direito de exigir o respeito à sua identidade étnica e cultural, não só do Estado, mas de toda a coletividade, exercitando a sua liberdade individual de reprodução étnica e cultural, um direito negativo, de primeira dimensão (reinterpretado sob as premissas democráticas dos direitos sociais, de segunda dimensão, que alargaram o sentido das liberdades liberais originárias) ${ }^{22}$.

Outra de natureza coletiva, um direito fundamental de terceira geração, titularizado por todo o povo brasileiro, de ver respeitado e protegido nosso patrimônio cultural. Um direito que reivindica uma postura ativa dos Poderes Públicos que deve proporcionar os meios jurídicos e materiais necessários à realização dos direitos culturais, por meio de leis que tutelem o bem jurídico e de políticas públicas de sua efetivação concreta.

\section{DIREITO DE CONSULTA AOS POVOS INDÍGENAS}

A Constituição Federal brasileira, muito embora tenha garantido aos índios a posse permanente sobre as terras que habitam tradicionalmente, bem como o usufruto exclusivo das riquezas do solo, dos lagos e dos rios nelas existentes, possibilitou, mediante a observância de alguns requisitos, descritos nos arts. 231, § $3^{\circ}$ e 176, § 1ํㅡㄹ a exploração por terceiros dos recursos hídricos, incluídos os potenciais energéticos, e das riquezas minerais existentes em terras indígenas. Entre esses requisitos exigiu a oitiva das comunidades indígenas impactadas pelo empreendimento. Essa oitiva consubstancia o chamado direito de consulta às comunidades.

A Constituição nada mais menciona acerca da oitiva das comunidades, apenas determina a sua realização em face da exploração minerária, dos potencias hidrelétricos e energéticos em terras indígenas. A sua previsão liga-se à finalidade constitucional de garantir aos indígenas direitos sobre as terras que ocupam e o usufruto exclusivo das riquezas naturais, tudo voltado a proporcionar o seu bem-estar e a sua reprodução física e cultural.

22 Essa liberdade ainda poderá ser exercida coletivamente pelas comunidades indígenas, no que José Afonso chama de direitos individuais de expressão coletiva (Curso de Direito constitucional positivo. 24. ed. São Paulo: Malheiros, 2005), tanto é assim, que a Constituição, em seu art. 232, assegura a qualquer índio, ou a suas comunidades, legitimidade para ingressar no Poder Judiciário na defesa de seus direitos e interesses. 
A terra ocupada tradicionalmente pela comunidade, onde o índio nasceu e se criou e onde os seus antepassados se encontram sepultados, promove um resgate histórico e espiritual que conecta o indígena à sua "mãe terra" de uma maneira tal que a realização de sua dignidade se encontra dependente da manutenção desse vínculo. Dessa forma, a única maneira encontrada pelo ordenamento de promover a reprodução física e cultural dos índios foi garantir os direitos territoriais às comunidades indígenas ${ }^{23}$.

Dessa forma, se a ordem constitucional garantiu a posse permanente dos índios sobre as terras que tradicionalmente ocupam, não seria muito democrático permitir que empreendimentos econômicos de grande porte, tais como a mineração e a exploração energética ${ }^{24}$, fossem avalizados em suas terras (constitucionalmente deferidas) sem que Ihes fosse oportunizado se manifestar a respeito e influenciar na decisão dos Poderes Públicos quanto à viabilidade, ou não, do empreendimento.

Assim, fazendo jus ao princípio democrático, a Carta assegurou o direito de consulta sempre que grandes empreendimentos econômicos pretendam se instalar nas terras indígenas, de modo que seja oportunizado aos habitantes dessa terra participação na tomada da decisão que lhes afetará por demais, além de fornecer informações acerca do empreendimento e promover o entendimento entre Estado/comunidade/empresa. Negar essa consulta, além de inconstitucional, seria antidemocrático.

Pois bem, investigando mais a fundo, temos, então, que o direito de consulta apresenta natureza de direito fundamental, posto que inarredável da dignidade indígena, uma vez que pretende ouvir a manifestação dos próprios índios quanto a empreendimentos altamente impactantes e ambientalmente degradantes que se pretendem instalar em suas terras.

A consulta representa um forte instrumento democrático que a Constituição depositou entre o rol de direitos fundamentais dos povos indígenas, voltados à materialização de sua dignidade. A consulta visa a afastar os comportamentos históricos consagrados pelo Estado brasileiro que sempre ignorou as necessidades e os interesses dos povos indígenas, ou porque os consideravam incapazes de responder por si mesmos ou porque os consideravam às margens da sociedade brasileira.

23 A Declaração da ONU sobre os direitos dos povos indígenas, aprovada em 13.09.2007, pela Assembleia- Geral da ONU, em Nova York, também ressalta a importância dessa ligação do indígena com sua terra e com os recursos naturais, assegurando como direitos de os indígenas não ser forçosamente assimilados e nem destituídos de sua cultura.

24 Ressalte-se que tanto os recursos minerais quanto os potenciais de energia hidráulica constituem bens da União, podendo a sua exploração ser concedida a terceiros, observados os requisitos constitucionais (art. 176, caput e $\S 1^{\circ}$, somado ao art. 20, VIII e IX, da Constituição Federal). 
Indo mais além, seria um direito fundamental de feição mista, uma vez que configura claramente um direito à prestação, jurídica e material, e de participação. Nos debruçaremos melhor sobre cada uma dessas qualificações.

\subsection{A CONSULta COMO UM DIREITO FUndaMENTAL À PRESTAÇÃo}

No bojo da teoria geral, encontramos a tradicional classificação dos direitos fundamentais em direitos de defesa, direitos de prestação e direitos de participação ${ }^{25}$.

Os direitos de defesa corresponderiam àquelas clássicas liberdades negativas, os direitos de primeira dimensão, oponíveis primordialmente ao Estado que deveria se abster de interferir na liberdade dos indivíduos. Seria o status negativo de Jellinek ${ }^{26}$. Em regra, são autoaplicáveis.

Já os direitos de prestação são aqueles direitos de caráter eminentemente social, que exigem uma prestação do Estado, um fazer voltado a estabelecer uma igualdade efetiva entre os indivíduos, satisfazendo as suas necessidades. Os direitos prestacionais somente se realizam por meio do Estado e a sua satisfação possibilita o real desfrute das liberdades pelos indivíduos. Correspondem aos chamados direitos de segunda dimensão, nascidos das reivindicações operárias e populares por melhores condições de vida durante o desenvolvimento do capitalismo industrial, no final do século XIX e início do século XX. Seria o status positivo, ou civitatis, de Jellinek.

Os direitos de prestação correspondem a uma obrigação do Estado de dar ou de fazer uma prestação material ou jurídica. Alguns desses direitos se satisfazem apenas com uma prestação jurídica, e o Estado atua normativamente disciplinando o objeto do direito, como quando cria uma lei penal para coibir o terrorismo e o racismo ${ }^{27}$.

Já a prestação material satisfaz efetivamente uma necessidade social (direito à prestação em sentido estrito), e o Estado deve promover uma obra ou um serviço público ou fornecer bens. A maioria dos direitos sociais se satisfaz dessa maneira, por meio de uma utilidade pública promovida pelo Estado. Desses direitos à prestação material temos aqueles que podem ser exigidos de imediato, bastando a sua previsão constitucional para fazer surgir um direito subjeti-

25 Paulo Gustavo Gonet chama a atenção que, quanto aos direitos de participação, não existe um consenso na doutrina se realmente seria uma terceira classificação, ao lado dos direitos de defesa e de prestação, ou se estaria incluído naqueles. Salienta, ainda, que tanto Canotilho como Alexy não consideram os direitos de participação como um terceiro grupo. Aspectos de teoria geral dos direitos fundamentais. In: MENDES, Gilmar Ferreira; COELHO, Inocêncio Mártires; BRANCO, Paulo Gustavo Gonet. Hermenêutica constitucional e direitos fundamentais. Brasília: Brasília Jurídica, 2000. p. 151.

26 No final do século passado, Georg Jellinek desenvolveu a teoria dos quatro status que um indivíduo poderia se encontrar em face do Estado: status passivo, status negativo, status ativo e status positivo.

27 Exemplo que tomamos emprestado de Paulo Gustavo Gonet (Op. cit., p. 144). 
vo para o destinatário da norma (direitos originários à prestação), como temos aqueles direitos cuja efetividade depende de uma intermediação legislativa.

Para essa segunda categoria de direitos prestacionais, a eficácia da norma constitucional fica dependente de uma ação normativa do Poder Legislativo, antes da qual não se tem um direito subjetivo exigível de pronto dos Poderes Públicos, bem como resta limitado pela reserva do financeiramente possível. Entramos, então, na seara da discricionariedade administrativa, possuindo o gestor da coisa pública um razoável grau de liberdade nas escolhas que realizará. Ao Judiciário não é dado extrair direitos subjetivos das normas constitucionais de eficácia limitada ${ }^{28}$, mas apenas das prestações postas nas normas que as disciplinam. Restando, como controle jurisdicional, a inconstitucionalidade por omissão.

Os direitos de participação seriam aqueles que oportunizam a participação do indivíduo na tomada de decisões relevantes para o País, basicamente os direitos políticos, exercidos pelos cidadãos.

Fornecidas essas informações básicas, voltemos à questão do direito à consulta. Claramente a consulta se coloca como um direito à prestação material que exige uma atuação normativa do legislador.

A própria exploração dos recursos minerais, potenciais hidrelétricos e energéticos em terras indígenas, depende de uma atuação normativa por parte do legislador para que possa ocorrer constitucionalmente. Isso porque o art. 176, § 1ํㅡㄹ exigiu uma legislação específica a regular tais empreendimentos, como condição para que ocorram em território índio.

Saliente-se que essa regulação ainda não fora providenciada pelo legislador, existindo apenas projetos de leis ${ }^{29}$ dedicados à mineração em terras indígenas que tramitam há décadas no Congresso Nacional sem obter a devida aprovação, o que acaba por inviabilizar a realização dessa empreitada. No entanto,

28 José Afonso da Silva estrutura as normas constitucionais, segundo o seu grau de eficácia, em três grupos: as normas de eficácia plena (aptas a produzir a plenitude de seus efeitos de imediato); as normas de eficácia contida (normas que, apesar de nascerem aptas a produzir os seus efeitos de imediato, podem ter o seu alcance restringido por meio de legislação ulterior); e as normas de eficácia limitada (normas que somente terão sua eficácia completa a partir de uma regulação legal posterior, exigida pela Constituição). Vide: Aplicabilidade das normas constitucionais. São Paulo: Malheiros, 2008. passim.

29 A proposta que tramita hoje na Câmara dos Deputados (PL 1.610/1996) e que se destina a tratar especificamente da questão mineraria em terras índias foi iniciada pelo Senador Romero Jucá, tendo sido aprovada na respectiva Casa Legislativa, e seguiu à Câmara dos Deputados, onde tramita a mais de 10 anos. Em 2007, foi substituída por uma proposta do Governo, quando, então, fora instituída uma comissão especial para analisar o assunto, tendo sido, simplesmente, abandonada a discussão acerca do Estatuto das Sociedades Indígenas (PL 2.057), que também intentava regular a questão da mineração. Passado alguns meses, já em 2008, a comissão apresentou uma contraproposta substitutiva, encabeçada pelo seu então Relator, o Deputado Eduardo Valverde. Atualmente, agora sob a relatoria do Deputado Edio Lopes, a Câmara se articula no intento de promover uma consulta aos povos indígenas acerca do próprio PL da mineração, em um total de dez encontros previstos para o segundo semestre de 2015. 
o complexo hidrelétrico de Belo Monte avança em sua conclusão, afrontando todos os direitos constitucionais deferidos às comunidades indígenas e com o total respaldo de nossa Corte Suprema e do órgão indigenista.

Entre as exigências constitucionais que deveriam estar contempladas nessa legislação específica ${ }^{30}$, a fim de que se possa explorar minério, potenciais hidrelétricos e energéticos em terras indígenas, está a consulta às comunidades impactadas. Então temos um direito fundamental dos indígenas (direito a ser consultado), de obter uma prestação material do Poder Público (realizar a consulta antes de qualquer empreendimento adentrar suas terras), que está na dependência de uma prestação jurídica do Poder Legislativo (lei específica), regulando o procedimento de consulta de modo a fazer surgir um direito subjetivo das comunidades de serem consultadas.

Poderíamos até supor estar inviabilizado tal direito consultivo em face da omissão do nosso Parlamento em regular a questão; no entanto, quanto ao processo de consulta, o ordenamento brasileiro apresenta sim a regulação específica: A Convenção no 169 da Organização Internacional do Trabalho (OIT) convenção sobre povos indígenas e tribais em países independentes, firmada em Genebra, em 1989, que, entre outras coisas, disciplina o direito de consulta às comunidades indígenas ante a possibilidade de qualquer fato que possa lhes afetar diretamente, desde medidas legislativas até a presença de empreendimentos econômicos em suas terras ${ }^{31}$, tendo sido devidamente ratificada (Decreto Legislativo $\mathrm{n}^{\mathrm{0}}$ 143/2002) e incorporada ao nosso ordenamento jurídico por meio do Decreto no 5.051 , de 2004 .

Por ter sido devidamente incorporada à nossa ordem jurídica com status de lei ordinária, a Convenção no 169 da OIT deve ser chamada a incidir sempre que empreendimentos econômicos possam afetar comunidades indígenas, devendo ser realizado o processo consultivo previamente e em cumprimento de todos os termos postos pela referida norma.

É de se salientar que a exploração de recursos minerários, potenciais hidrelétricos e energéticos em terras indígenas, ainda carece de regulação espe-

30 Os requisitos postos pela Constituição, além da legislação específica e da consulta às comunidades envolvidas, temos a participação dos índios no resultado da lavra, autorização do Congresso Nacional e exploração operada por empresa brasileira ou constituída sob as leis brasileiras, com cede e administração no País. Consultar os arts. 231, § $3^{\circ}$, e 176, $\S 1^{\circ}$. Mais detalhes, vide: FEIJÓ, Julianne Holder da C. S. Empreendimentos energéticos em terras indígenas: uma análise constitucional à luz do multiculturalismo. Argumentum - Revista de Direito, Marília/SP: Unimar, n. 15, p. 65, 2014.

31 "Art. 15. [...] 2. Em caso de pertencer ao Estado a propriedade dos minérios ou dos recursos do subsolo, ou de ter direitos sobre outros recursos, existentes na terras, os governos deverão estabelecer ou manter procedimentos com vistas a consultar os povos interessados, a fim de se determinar se os interesses desses povos seriam prejudicados, e em que medida, antes de se empreender ou autorizar qualquer programa de prospecção ou exploração dos recursos existentes nas suas terras. Os povos interessados deverão participar sempre que for possível dos benefícios que essas atividades produzam, e receber indenização equitativa por qualquer dano que possam sofrer como resultado dessas atividades." 
cífica para que possam se realizar constitucionalmente. Mas quanto à consulta, essa ausência normativa não terá o condão de afastar a realização do procedimento, dado que já existe a regulação da matéria.

Com efeito, nenhum daqueles empreendimentos supracitados poderia estar ocorrendo em terras indígenas ante a ausência da legislação específica; entretanto, o Estado brasileiro sistematicamente vem desconsiderando essa exigência constitucional. Os títulos minerários são concedidos em terras indígenas pelo Departamento Nacional de Produção Mineral (DNPM) ${ }^{32}$, e o complexo hidrelétrico de Belo Monte avança olvidando os direitos constitucionais dos indígenas, descumprindo os compromissos assumidos quando do início das obras. No passado, as hidrelétricas de Tapajós, Tucuruí e Balbina foram concluídas sem realizar o procedimento consultivo exigido pela Constituição ${ }^{33}$.

O Estado brasileiro, ao adotar tais comportamentos - além de enfraquecer a força normativa de nossa Constituição ${ }^{34}$, negligenciando direitos fundamentais que ele deveria promover, faltando com o seu papel democrático de Estado provedor, fazendo letra morta de dispositivos constitucionais -, ainda descumpre os compromissos internacionais que assumiu perante outras Nações soberanas, sofrendo, inclusive, retaliações nesse sentido ${ }^{35-36}$. Com efeito, os Estados que ratificam obrigações no plano internacional passam a se submeter à autoridade das instituições internacionais quanto à tutela e à fiscalização do cumprimento dessas obrigações no plano nacional ${ }^{37}$.

Aliás, frise-se que a Constituição brasileira elegeu, em seu art. 4ํㅡㄴ, II, a prevalência dos direitos humanos como princípio fundamental a reger as suas relações internacionais. Nada mais coerente, portanto, que assuma compromissos internacionais voltados a equacionar problemas envolvendo a concretiza-

32 FEIJÓ, Julianne Holder da C. S. Exploração de petróleo em terras indígenas: à procura de um marco legal. Revista Direitos Culturais, Santo Ângelo, v. 5, n. 9, p. 167-168, jul./dez. 2010.

33 Instituto Socioambiental. A dívida de Belo Monte. Disponível em: <http://www.socioambiental.org/sites/blog. socioambiental.org/files/blog/pdfs/placar_geral_integrado_belo_monte.pdf > . Acesso em: 17 maio 2015.

34 HESSE, Konrad. A força normativa da Constituição. Trad. Gilmar Ferreira Mendes. Porto Alegre: Fabris Editor, 1991. p. 21.

35 Em setembro de 2010, a ONU emitiu um relatório chamando a atenção do Brasil pelo desrespeito aos direitos humanos dos povos indígenas e, sobretudo, pela inobservância do direito de consulta dos povos afetados pelo Complexo Hidrelétrico de Belo Monte, no Rio Xingu, Estado do Pará. Maiores informações, vide: FEIJÓ, Julianne Holder da C. S. Op. cit., 2014, p. 67 (A2).

36 Da mesma maneira, o Brasil fora denunciado perante a Comissão Interamericana de Direitos Humanos por descumprimento de direitos fundamentais dos povos Yanomamis, em Roraima, tanto pela ausência de políticas públicas e desrespeito à vida, liberdade e integridade desses índios, quando da abertura da BR 210, nos idos do Regime Militar, como pela chacina de Haximu, promovida por garimpeiros contra os índios Yanomamis, ao total descaso do Governo brasileiro. A denúncia ocasionou um verdadeiro "puxão de orelha" pela Comissão Interamericana ao Estado brasileiro e uma série de recomendações que ainda quedam sem cumprimento (PIOVERSAN, Flávia. Op. cit., 2010, p. 322-323).

37 PIOVERSAN, Flávia. Op. cit., 2010, p. 9. 
ção dos direitos humanos; a falta de coerência está em não realizar o que se comprometeu.

Inclusive, em um Estado Democrático de Direito temos como muito forte o princípio da máxima efetividade das normas constitucionais, não sendo admitido que um princípio fundamental, dedicado a guiar a ação internacional do Estado brasileiro, seja descumprido sistematicamente. O princípio fundamental é o princípio estruturante, destinado ao Estado, ostentando máxima efetividade e aplicação imediata, não podendo ser olvidado. Por outro lado, garantir a primazia dos direitos humanos vai mais além do que a simples elaboração de normas internacionais, tutelando-os, implica assegurar a plena integração dessas normas no âmbito da ordem jurídica interna ${ }^{38}$.

Saliente-se, por fim, que também a Declaração da ONU sobre os direitos dos povos indígenas ${ }^{39}$ assevera a necessidade de realizar um processo consultivo às comunidades indígenas antes da realização de qualquer empreendimento econômico em suas terras ou a adoção de medidas legislativas. $\mathrm{O}$ instrumento ainda ressalta o direito à autodeterminação dos povos indígenas e a sua liberdade e independência na tomada de decisões acerca de seus modos de viver e se desenvolver.

Ressalte-se que o Brasil, juntamente com 142 países $^{40}$, votou a favor da Declaração, devendo manter o compromisso firmado perante a ordem internacional, de modo a não perder prestígio e credibilidade frente às outras Nações. Apesar de não ter força vinculante, a Declaração deve servir de orientação na realização de políticas públicas, na tomada de decisões judiciais e na adoção de medidas legislativas pelo Estado brasileiro, já que reflete o seu compromisso, assumido perante os demais Estados nacionais, para com os povos indígenas.

Destaque-se uma forte tendência da doutrina mais moderna ${ }^{41}$ em reconhecer aos tratados de direitos humanos assinados pelo País o status de norma constitucional, por encerrarem direitos materialmente fundamentais, integrando o bloco de materialidade constitucional, muito embora não estejam escritos no texto maior. No Brasil, essa posição se arrima no $\S 2^{\circ}$ do art. $5^{\circ}$ da Constitui-

38 Idem, p. 40.

39 Aprovada pela ONU em 13.09.2007, em Nova York, durante sessão do Fórum Permanente da ONU para assuntos indígenas, o documento é fruto dos trabalhos de uma comissão específica sobre as populações indígenas, criada pela ONU em 1982. O texto reflete as reivindicações atuais dos povos indígenas do mundo, principalmente quanto ao seu relacionamento com os Estados nacionais, bem-estar e autodeterminação.

40 Votaram contra o documento: Estados Unidos, Canadá, Austrália e Nova Zelândia, muito embora esses dois últimos tenham posteriormente aderido ao feito em 2009 e 2010, respectivamente. A quase totalidade da América Latina, com exceção da Colômbia, que se absteve, votou favoravelmente ao documento. Maiores informações: Unesco. Declaração das Nações Unidas sobre os Direitos dos Povos Indígenas: perguntas e respostas. Brasília, 2008. Disponível em: <http://unesdoc.unesco.org/images/0016/001627/162708POR. pdf > . Acesso em: 29 jun. 2015.

41 Defendem essa abertura constitucional: Jorge Miranda, Canotilho, José Afonso da Silva, Cançado Trindade, Konrad Hesse, dentre outros ilustres constitucionalistas. Vide: PIOVERSAN, Flávia. Op. cit., 2010, p. 43-85. 
ção Federal brasileira, a chamada cláusula de abertura, e, apesar de não lograr adesão majoritária por parte dos Ministros da Suprema Corte, nela encontrou alguns adeptos ${ }^{42}$.

Por fim, saliente-se que a chamada cláusula de abertura, encerrada no art. $5^{\circ}, \S 2^{\circ}$, da Constituição brasileira, ao consagrar o status de materialidade constitucional aos tratados internacionais de direitos humanos, não está a criar nenhuma novidade jurídica no direito ocidental; pelo contrário, apenas está embarcando na nova tendência constitucional. De fato, as Constituições do Peru, da Argentina, da Venezuela e da Nicarágua asseguram hierarquia constitucional aos tratados de direitos humanos, restando ao Brasil reconhecer a amplitude do alcance de seu dispositivo de abertura ${ }^{43}$.

\subsection{A consulta COMO UM DIREITO FUNDAMENTAL dE PARTIIIPAÇ̃̃o}

Deixada as polêmicas de lado - se os direitos de participação seriam uma terceira categoria, ao lado dos direitos negativos e de prestação, ou se estariam neles incluídos -, o fato é que existem determinados direitos constitucionais voltados à participação ativa do cidadão na vida da comunidade política, são os direitos políticos, o status ativo de Jellinek. Tais direitos oportunizam ao indivíduo exercer a sua cidadania, contribuindo para a formação da vontade nacional nas decisões de maior relevância.

É bem verdade que a audiência pública ostenta essa característica de exercício da cidadania; contudo, não se confunde com o processo consultivo, não suprindo essa necessidade. As audiências públicas dirigem-se aos cidadãos em geral, para que se inteirem, tirem dúvidas e opinem sobre questões relevantes. A consulta constitucional volta-se especificamente às comunidades indígenas impactadas por algum empreendimento econômico (mineração e exploração de recursos hidrelétricos e energéticos), destinada a dar voz aos povos envolvidos, de modo que influenciem na tomada da decisão, bem como deverá prestar esclarecimentos e informações.

Assim como a audiência pública, a consulta se revela um verdadeiro instrumento de cidadania, possibilitando que as comunidades envolvidas tenham acesso a informações e esclarecimentos relevantes, bem como opinem quanto à presença do empreendimento em suas terras, sugerindo medidas que mitiguem os impactos ocasionados ou rejeitando a sua possibilidade. Negar a consulta aos povos indígenas é negar-Ihe participação política em um processo que lhes

42 No julgamento do Recurso Extraordinário n 466.343 (que analisava a questão da inconstitucionalidade da prisão civil do depositário infiel em face do pacto de São José da Costa Rica) restaram vencidos os Ministros Celso de Mello, Cesar Peluso, Ellen Grace e Eros Grau, que conferiam aos tratados internacionais de direitos humanos status constitucional. Maiores detalhes: PIOVERSAN, Flávia. Op. cit., 2010, p. 77.

PIOVERSAN, Flávia. Op. cit., 2010, p. 84. 
irá afetar diretamente, configurando uma verdadeira afronta ao princípio democrático e a sua liberdade e autodeterminação. Se não fosse imprescindível a sua realização, não estaria exigida expressamente em um dispositivo constitucional.

A consulta consubstancia um instrumento de intermediação política entre os Estados independentes e as comunidades indígenas neles existentes, representando uma importante ferramenta da efetivação dos seus direitos fundamentais, garantindo o direito da comunidade de se autodeterminar, escolhendo o seu destino, resguardando a posse plena dos autóctones sobre as suas terras e sobre a exploração exclusiva dos recursos naturais existentes, bem como satisfaz o direito à preservação de sua cultura, suas crenças e suas tradições a partir do momento que propicia aos indígenas a escolha de querer, ou não, que seu modo de vida seja devassado e misturado ao modus vivendi "civilizado".

Esse foi o raciocínio que norteou a Conferência das Nações Unidas para o Meio Ambiente e Desenvolvimento, realizada no Rio de Janeiro, em 1992, e que deu origem à Agenda 21 da $\mathrm{ONU}^{44}$ cujo item 26.3, prevê a necessidade dos Governos e das organizações intergovernamentais reconhecerem que as terras das comunidades indígenas devem ser protegidas contra atividades ambientalmente insalubres ou consideradas inadequadas social e culturalmente pela comunidade indígena, consagrando o direito dos grupos tribais em se autodeterminar, escolhendo as suas prioridades, em perfeita sintonia com o estabelecido no art. $7^{\circ}$, item 1, da Convenção n⿳0 $169 / \mathrm{OIT}^{45}$.

Muito se tem falado até aqui sobre esse direito de autodeterminação dos povos indígenas. De fato, em torno da questão grandes debates já foram travados no cenário internacional, de modo que hodiernamente já se solidificou o entendimento de que essa autodeterminação não corresponderia à soberania na seara internacional ou a independência frente aos Estados nacionais.

Os povos indígenas não são nações politicamente independentes, mas devem ter assegurada a liberdade de gestão interna, de escolha de seus processos e modo de vida sem que sofram as imposições déspotas do passado, quando o Estado tomava decisões por demais impactantes sem levar em consideração os interesses e as necessidades dos indígenas. Tais políticas geraram impactos

44 Em 1992, representantes de 170 países reuniram-se no Rio de Janeiro, na Conferência das Nações Unidas para o Meio Ambiente e Desenvolvimento, conhecida como "Rio 92", cuja finalidade era discutir a crise ambiental e a sobrevivência da humanidade no Planeta. Dessa conferência resultou a Agenda 21, documento internacional de compromissos ambientais e recomendações para um novo modelo de desenvolvimento (o desenvolvimento sustentável), enfatizando a importância da educação ambiental como estratégia de sobrevivência da humanidade.

45 In verbis: "Art. $7^{\circ}[\ldots]$ 1. Os povos interessados deverão ter o direito de escolher suas, próprias prioridades no que diz respeito ao processo de desenvolvimento, na medida em que ele afete as suas vidas, crenças, instituições e bem-estar espiritual, bem como as terras que ocupam ou utilizam de alguma forma, e de controlar, na medida do possível, o seu próprio desenvolvimento econômico, social e cultural. Além disso, esses povos deverão participar da formulação, aplicação e avaliação dos planos e programas de desenvolvimento nacional e regional suscetíveis de afetá-los diretamente. [...]" 
tão desastrosos que, em muitos casos, conduziram à dizimação de comunidades inteiras ou a sua drástica redução. Foram retiradas forçadas dos indígenas de suas terras originárias, construção de rodovias que cortaram ao meio terras indígenas, construção de hidrelétricas que os desalojaram, concessão de títulos minerários e exploração de petróleo em suas terras, entre inúmeras outras medidas tomadas pelo Estado brasileiro, à total revelia dos índios, que prejudicaram comunidades inteiras.

Os arts. $3^{\circ}$ e $4^{\circ}$ da Declaração das Nações Unidas sobre os direitos dos povos indígenas, além de reconhecer a autodeterminação, salientando a sua liberdade na busca do desenvolvimento econômico, social e cultural, ainda esclarecem que o direito à autodeterminação está relacionado ao direito dos povos indígenas ao autogoverno e à autonomia no que diz respeito a seus assuntos internos e locais. Não se confundindo com a autodeterminação dos Estados soberanos. Como bem já esclareceu o Supremo Tribunal no caso da demarcação da Terra Indígena Raposa Serra do Sol ${ }^{46}$, as comunidades indígenas não possuem soberania, as suas terras não correspondem a territórios no sentido político da expressão, consubstanciando uma realidade sociocultural.

Dessa forma, a consulta surge como uma medida a garantir que as decisões que possam afetar os povos indígenas não sejam mais tomadas à sua revelia, como historicamente ocorreu, não só no Brasil, mas em todos os países americanos que negligenciaram os seus indígenas por séculos. Daí a nota da fundamentalidade que constitui o direto de consulta: incluir os indígenas nas decisões que Ihes afetem, permitindo-Ihes participação política e voz na tomada de decisões, cumprindo o princípio democrático, único caminho para lhes assegurar uma vida em dignidade.

\subsection{0 diRetTo de CONSULta Na CONUENÇÃo N ${ }^{0} 169$ da OIT}

Tendo sido regulada pela OIT, em sua Convenção no 169 , assinada em Genebra, em 1989, que fora incorporada ao ordenamento pátrio com status de lei ordinária, por meio do Decreto no 5.051/2004, a consulta às comunidades impactadas pela exploração de recursos minerais, potenciais hidrelétricos e energéticos deverá, conforme estipulado pela Constituição Federal, ser realizada nos moldes e termos da citada Convenção, juntamente com o programa contido na Agenda 21 da ONU, que estabelece um procedimento sobre o qual nos debruçaremos a seguir.

Por conseguinte, a consulta é inafastável de qualquer procedimento que vise a conceder a exploração e produção hidrelétrica, energética e minerária, inclusive de petróleo e gás natural, em terras indígenas, sob o risco de macular 
a referida concessão com o vício da inconstitucionalidade, posto que a própria Carta Fundamental prevê a oitiva das comunidades impactadas como requisito para a realização dessas atividades em suas terras, e o faz no intuito de assegurar o direito dos indígenas à continuidade física e cultural, a exclusividade do uso de suas terras e dos recursos naturais indispensáveis à sua sobrevivência.

Portanto, inegável que o exercício do direito de consulta gera o direito das comunidades indígenas a dizer "não". O importante é permitir à tribo que descida o seu próprio destino, fazendo valer as suas garantias constitucionalmente asseguradas; do contrário, o direito à consulta, previsto na Convenção no 169 da OIT e em nossa Carta Constitucional, cairia no vazio, seria uma mera formalidade a ser cumprida, sem, contudo, alcançar a finalidade de permitir que a comunidade índia participe dos atos decisórios que lhes afetam.

O art. 6º da Convenção no 169 da OIT traz uma "cláusula geral" de consulta, onde são identificados os seus elementos essenciais: 1) A consulta deve ocorrer quando medidas legislativas ou administrativas devam afetar a comunidade; 2) sempre deverá ser prévia a tomada de qualquer decisão; 3) A legitimidade da consulta depende da participação das instituições representativas dos povos interessados; 4) Deve ser de boa-fé; 5) Os resultados e produtos da consulta devem refletir na decisão final.

Quanto ao primeiro item, não podemos olvidar que a obrigatoriedade da realização da consulta atinge inclusive a atividade legislativa, estando os projetos de leis voltados aos indígenas sujeitos a consultar as comunidades indígenas do País, visto que a elas interessa sobremaneira. Deve ser realizada previamente à promulgação da lei, uma vez que a intenção da Convenção é consagrar a consulta como um instrumento de participação dos silvícolas nas decisões mais importantes que afetam os seus interesses.

Neste particular, o Tribunal Constitucional colombiano se manifestou por diversas vezes pela inconstitucionalidade do decreto que regula o procedimento de consulta, por não ter ele realizado previamente uma consulta sobre o seu próprio conteúdo ${ }^{47}$. A Colômbia é o País que possui a mais vasta jurisprudência relacionada à efetivação da cláusula geral de consulta prevista no Convenção no 169 da OIT, principalmente quanto à necessidade de sua observância na ceara legislativa ${ }^{48}$.

Entre as maiores conquistas das comunidades tradicionais obtidas junto à Corte Constitucional do País estão a interpretação da Convenção no 169 como

47 FEIJÓ, Julianne Holder da C. S. Op. cit., 2014, p. 62 (A1).

48 INSTITUTO SOCIOAMBIENTAL. Consulta prévia sobre medidas legislativas na Colômbia. Consulta livre, prévia e informada na Convenção no 169 da OIT. Disponível em: <http://www.socioambiental.org/inst/esp/consulta_ previa/?q=node/20>. Acesso em: 27 jun. 2015. 
parte do bloco de constitucionalidade, segundo uma lógica da materialidade constitucional, e o reconhecimento de que o direito de consulta consubstancia um direito fundamental das comunidades indígenas e tribais.

Já, no Equador, as comunidades indígenas consideram tão lesiva a legislação interna, também promulgada sem observar o devido processo de consulta, que se negam, inclusive, a participar de processo consultivo por ela regulado, estando, atualmente, questionando a sua legitimidade junto à Corte Interamericana de Direitos Humanos $(\mathrm{CIDH})^{49}$.

Quanto à exigência de que a consulta se dê mediante a participação das instituições representativas dos povos envolvidos, percebe-se a nítida inspiração multicultural e pluriétnica da Convenção, indicando a sua sintonia com as mais modernas correntes de preservação e reprodução de culturas e tradições etnicamente diferenciadas, reconhecendo não só a autonomia desses povos, o seu direito de autodeterminação, como também significa o reconhecimento jurídico da representação dessas comunidades segundo os seus costumes e as suas tradições.

Caciques, Xamãs, Conselhos de anciãos, associações, não importa, terá legitimidade aquelas instituições representativas reconhecidas pela comunidade, com poder para falar em nome dela e tomar decisões. Na Bolívia, além da legitimidade da representação, exige-se, ainda, a ratificação do acordo firmado pela respectiva comunidade, de forma a assegurar que o conteúdo da decisão tomada corresponde realmente aos interesses do grupo.

Importante salientar que a Fundação Nacional do Índio (Funai) não possui essa prerrogativa, pois que se trata de instituição integrante da estrutura indireta da Administração Pública, não possuindo legitimidade para intervir no processo de consulta em nome de qualquer comunidade indígena, a não ser a fim de elaborar parecer ou facilitar a aproximação entre o Governo e os índios.

Outrossim, conforme o abalizado entendimento do Tribunal Regional Federal da 1ํㅡㄹ Região (muito embora não seja o posicionamento assumido pela Suprema Corte no caso da hidrelétrica de Belo Monte ${ }^{50}$ ), o único competente

49 A Comissão Interamericana de Direitos Humanos tem por objetivo promover a observância e a proteção dos direitos humanos na América, alcançando todos os Estados signatários da Convenção Americana de Direitos Humanos de 1969 (Pacto São José da Costa Rica) e Estados-membros da Organização dos Estados Americanos (OEA), tendo legitimidade para encaminhar reclamações contra os casos de violação aos direitos humanos qualquer indivíduo ou grupo de indivíduos. A Comissão Interamericana de Direitos Humanos possui, ainda, legitimidade para submeter causas ao julgamento da Corte Interamericana de Direitos Humanos.

50 A referida decisão daquele TRF fora derrubada pelo entendimento do Supremo Tribunal Federal, em decisão monocrática da então Presidente Ministra Ellen Gracie, que, além de permitir a realização da consulta pelo Ibama, ainda reconheceu a validade do Decreto $n^{\circ} 788 / 2005$, que autorizou a construção do complexo hidrelétrico Belo Monte sem consultar as comunidades impactadas. Vide: FEIJÓ, Julianne Holder da C. S. Op. cit., 2014, p. 67 (A1). Posteriormente, em 13 de agosto de 2012, o citado TRF determinou a paralisação da obra até que fosse realizado o procedimento de consulta. Novamente, em decisão monocrática de 27 de 
para a realização da consulta prévia é o Congresso Nacional, haja vista que a Constituição Ihe deferiu a atribuição de autorizar a exploração minerária e o aproveitamento dos recursos hídricos e energéticos em terras indígenas, não sendo, sequer, possível a sua delegação ${ }^{51}$. Além do mais, a consulta prévia consubstancia um dever da Casa Legislativa, e não uma mera faculdade, vez que, além de estar determinada na Constituição como requisito para a exploração minerária e energética em território aborígene, também integra o leque de direitos fundamentais dessa gente.

O Instituto Socioambiental (ISA) ${ }^{52}$ ainda alerta que se na decisão final não estiverem refletidas as opiniões debatidas nas reuniões, estas não poderão ser consideradas como um processo de consulta, vez que não cumpriu a sua finalidade institucional. Neste aspecto, narra o ISA que a legislação boliviana é a única empenhada em tornar o processo de consulta um verdadeiro instrumento de negociação, condicionando o seu produto final ao consenso dos envolvidos no processo consultivo, diferentemente do que faz seus vizinhos latinos que entendem que a palavra final consiste em ato unilateral do Governo, reduzindo o direito fundamental dos índios à consulta em uma mera formalidade a ser cumprida, acabrunhando a própria força normativa da Carta Constitucional.

\section{CONCLUSÕES}

Preocupada em proteger a identidade étnica e cultural dos diversos grupos participantes do processo civilizatório nacional, a Constituição Federal brasileira dedicou um capítulo à proteção dos direitos culturais, entendidos não só como o direito individual de acesso à cultura, mas também à tutela, de titularidade coletiva, às referências, à memória e aos modos de fazer e de viver de grupos culturalmente singulares, tais como os indígenas e quilombolas.

agosto de 2012, o STF suspendeu a decisão daquela Corte, agora na presidência do Ministro Ayres Britto. Prosseguindo Belo Monte de vento em polpa.

51 Conferir a jurisprudência da Corte: "[...] A questão jurídica controvertida nesse tópico diz respeito se o Congresso Nacional pode delegar a oitiva das comunidades indígenas afetadas. A Constituição não oferece uma resposta conclusiva. É preciso examinar-se a questão em conformidade com os princípios que regem a defesa das comunidades indígenas. A primeira constatação que se tem da mera leitura do $\S 3^{\circ}$ do art. 231 da CF/1988 é a obrigatoriedade da consulta às comunidades indígenas afetadas. A hipótese não é de faculdade do Congresso Nacional. O constituinte ordenou que sejam 'ouvidas as comunidades afetadas para que participem da definição dos projetos que afetarão suas terras e seu modus vivendi'. A consulta se faz diretamente à comunidade envolvida com o projeto de construção. Não há se falar em consulta à Funai a qual poderá emitir parecer sobre o projeto, mas não substitui a vontade dos indígenas. Portanto, a consulta é intuito personae. Essa problemática não está sendo discutida neste agravo, mas sua abordagem esclarece a intenção do legislador no tema do aproveitamento dos recursos naturais em terra indígena. Assim como a comunidade indígena não pode ser substituída por outrem na consulta, o Congresso Nacional também não pode delegar o ato. É o Congresso Nacional quem consulta, porque é ele que tem o poder de outorgar a obra. Quem tem o poder tem a responsabilidade pelos seus atos. [...]" (TRF 1a R., Ag 2006.01.00.017736-8/PA, $5^{\mathrm{a}}$ T., Rel ${ }^{\mathrm{a}}$ Des $^{\mathrm{a}}$ Fed. Selene Maria de Almeida, DJ 05.02.2007, p. 147).

52 INSTITUTO SOCIOAMBIENTAL. Consulta livre, prévia e informada na Convenção no 169 da OIT. Disponível em: <http://www.socioambiental.org/inst/esp/consulta_previa>. Acesso em: 10 ago. 2010. 
Dedicada a garantir a reprodução física e cultural dos povos indígenas, a Carta estruturou uma série de direitos voltados à satisfação de suas necessidades mais latentes, tais como a posse sobre as terras que tradicionalmente ocupam e o usufruto exclusivo das riquezas naturais nelas existentes, condicionando a exploração dos recursos minerais, dos potenciais hidrelétricos e energéticos à observância de requisitos expressos, entre eles o dever de realizar consulta aos povos impactados.

O direito dos povos indígenas de serem consultados, sempre que algum empreendimento pretenda se instalar em suas terras, surge como um direito fundamental das comunidades índias relacionado à realização da sua dignidade e do princípio democrático, ao viabilizar a sua autodeterminação e liberdade, possibilitando a sua inclusão na tomada de decisões que lhes afetem.

O direito de consulta surge, assim, como um direito fundamental, não inscrito no art. 5ํ da Constituição, de natureza híbrida, posto que encerra em si tanto um direito à participação política como um direito à obtenção de uma prestação do Estado, jurídica e material. O direito de consulta, ao ter sido regulado pela Convenção no 169 da OIT, incorporada ao nosso ordenamento como lei ordinária, torna-se um direito subjetivo das populações indígenas que se vejam às voltas com a exploração dos recursos minerais e energéticos em suas terras.

Negar a realização de tal direito, além de inconstitucional, é antidemocrático, reduzindo a credibilidade do País frente às outras nações junto as quais se obrigou em instrumentos como a Convenção no 169 da OIT e a Declaração das Nações Unidas sobre os direitos dos povos indígenas, além de enfraquecer a força normativa da Constituição ao negligenciar uma exigência expressa. $O$ Brasil precisa começar a efetivar os direitos constitucionais dos povos indígenas, bem como precisa cumprir as obrigações que assumiu no cenário internacional, principalmente quanto à observância dos direitos humanos, de modo a concretizar o status de Estado Democrático de Direito.

\section{REFERÊNCIAS}

ABREU, Haroldo. Para além dos direitos - Cidadania e hegemonia no mundo moderno. Rio de Janeiro: Editora UFRJ, 2008.

BARRETO, Helder Girão. Direitos indígenas: vetores constitucionais. Curitiba: Juruá, 2008.

BOTELHO, Marcos César. Os povos indígenas e o direito a terra: o Supremo tribunal Federal e o julgamento da demarcação da terra Raposa Serra do Sol. In: SIQUEIRA, Dirceu Pereira; BELINATI, Miguel (Coord.). Inclusão social e direitos fundamentais. São Paulo: Boreal, 2009. p. 261-277. 
INSTITUTO SOCIOAMBIENTAL. Consulta livre, prévia e informada na Convenção no 169 da OIT. Disponível em: <http://www.socioambiental.org/inst/esp/consulta_ previa/?q=o-que-e>. Acesso em: 27 jun. 2015.

. A dívida de Belo Monte. Disponível em: <http://www.socioambiental.org/ sites/blog.socioambiental.org/files/blog/pdfs/placar_geral_integrado_belo_monte.pdf>. Acesso em: 17 maio 2015.

. A polêmica da Usina de Belo Monte. Disponível em: <http://www.socioambiental.org/esp/bm/index.asp>. Acesso em: 2 jul. 2015.

FEIJÓ, Julianne Holder da C. S. Empreendimentos energéticos em terras indígenas: uma análise constitucional à luz do multiculturalismo. Argumentum - Revista de Direito, Marília/SP: Unimar, n. 15, p. 47-72 (A.1), 2014.

. A capacidade civil indígena. Revista Direitos Fundamentais e Justiça, v. 8, n. 28, p. 209-228 (A.2), jul./set. 2014.

. O direito indigenista no Brasil: transformações e inovações a partir da Constituição Federal de 1988. Revista da Faculdade Mineira de Direito da PUC de Minas Gerais, v. 17, n. 34, p. 274-304 (A.3), 2014.

. Exploração de petróleo em terras indígenas: à procura de um marco legal. Revista Direitos Culturais, Santo Ângelo, v. 5, n. 9, p. 157-178 (B.1), jul./dez. 2010.

. A casuística latino-americana de exploração de petróleo em terras indígenas: o desafio da concretização dos direitos humanos em prol das comunidades impactadas. Revista Direito Energia, Natal/RN, 2010. Disponível em: <http://www.periodicos.ufrn. br/direitoenergia/article/view/4230/3466>. Acesso em: 28 mar. 2015, p. 11 (B.2).

HÄBERLE, Peter. Estado Constitucional cooperativo. Trad. Marcos Augusto Maliska e Elisete Antoniuk. Rio de Janeiro: Renovar, 2007.

HESSE, Konrad. A força normativa da Constituição. Trad. Gilmar Ferreira Mendes. Porto Alegre: Fabris Editor, 1991.

. Constitución y Derecho Constitucional. In: BENDA, Ernst; MAIHOFER, Werner; VOGEL, Hans-Jochen; HESSE, Konrad; HEYDE, Wolfgang. Manual de Derecho Constitucional. 2. ed. Madri: Marcial, 2001. p. 1-15.

Significado de los derechos fundamentales. In: BENDA, Ernst; MAIHOFER, Werner; VOGEL, Hans-Jochen; HESSE, Konrad; HEYDE, Wolfgang. Manual de derecho constitucional. 2. ed. Madrid: Marcial, 2001. p. 63-115.

MENDES, Gilmar Ferreira; COELHO, Inocêncio Mártires; BRANCO, Paulo Gustavo Gonet. Hermenêutica constitucional e direitos fundamentais. Brasília: Brasília Jurídica, 2000.

MIRANDA, A. Gursen de (Coord.). O direito e o índio. Belém: Cejup, 1994.

NOBRE JÚNIOR, Edilson Pereira. Terras indígenas e aproveitamento de recursos hídricos para fins de exploração energética. In: XAVIER, Yanko Marcios de Alencar et al. (Org.). Energia e Constituição. Ceará: Konrad Adenauer, 2009. p. 83-109.

PIOVERSAN, Flávia. Direitos humanos e o direito constitucional internacional. 11. ed. São Paulo: Saraiva, 2010. 
RICARDO, Fany; ROLLA, Alicia (Org.). Mineração em terras indígenas na Amazônia brasileira. São Paulo: Instituto Socioambiental, 2005.

SANTILLI, Juliana. Socioambientalismo e novos direitos: proteção jurídica à diversidade biológica e cultural. São Paulo: Peirópolis, 2005.

SANTILLI, Márcio. Terras indígenas na Amazônia brasileira: subsolo bloqueado por interesses minerários In: RICARDO, Fany (Org.). Interesses minerários em terras indígenas na Amazônia legal brasileira. Doc. no 6 do Instituto Socioambiental, jul. 1999, p. 81-89. Disponível em: <http://www.socioambiental.org/banco_imagens/pdfs/14.pdf>. Acesso em: 12 ago. 2010.

SANTOS FILHO, Roberto Lemos. Apontamentos sobre o direito indigenista. Curitiba: Juruá, 2006.

. Índios, Convenção no 169 da OIT e o meio ambiente. Jus Navigandi, Teresina, ano 10, n. 1074, 10 jun. 2006. Disponível em: <http://jus2.uol.com.br/doutrina/texto. asp? ID=8499>. Acesso em: 25 jan. 2009.

SANTOS, Boaventura de Sousa (Org.). Reconhecer para libertar: os caminhos do cosmopolitismo multicultural. Rio de Janeiro: Civilização Brasileira, 2003. Disponível em: <http://books.google.com.br>. Acesso em: 16 maio 2011.

. Por uma concepção multicultural dos direitos humanos. Rio de Janeiro: Contexto Internacional, v. 23, jan./jun. 2001. p. 7-34. Disponível em: <http://www.boaventuradesousasantos.pt/media/pdfs/Concepcao_multicultural_direitos_humanos_Contextolnternacional01.PDF>. Acesso em: 22 maio 2011.

SEN, Amartya. Desenvolvimento como liberdade. Trad. Laura Teixeira Motta. São Paulo: Companhia das Letras, 2010.

SILVA, José Afonso da. Curso de direito constitucional positivo. 24. ed. São Paulo: Malheiros, 2005. . Aplicabilidade das normas constitucionais. São Paulo: Malheiros, 2008. . Ordenação constitucional da cultura. São Paulo: Malheiros, 2001.

SOUZA FILHO, Carlos Frederico Marés de. O renascer dos povos indígenas para o direito. Curitiba: Juruá, 2008.

SOUZA FILHO, Carlos Frederico Marés de; ARBOS, Kerlay Lizane. Mineração em terras indígenas, direitos humanos e o sistema interamericano de direitos humanos. Disponível em: <http://srvapp2s.urisan.tche.br/seer/index.php/direitosculturais/article/ viewFile/30/24>. Acesso em: 28 mar. 2015.

UNESCO. Declaração das Nações Unidas sobre os Direitos dos Povos Indígenas: perguntas e respostas. Brasília, 2008. Disponível em: <http://unesdoc.unesco.org/ images/0016/001627/162708POR.pdf>. Acesso em: 29 jun. 2015. 